\title{
EDUCATION AND TRAINING Emergency medicine as a foundation trainee: what I wish I'd known at the start
}

\author{
Author: Lianne Fakes ${ }^{\mathrm{A}}$
}

KEYWORDS: junior doctor, emergency medicine

DOI: $10.7861 /$ fhj.2020-0185

\section{Introduction}

Emergency medicine is a common rotation for foundation doctors to undertake. It affords a genuine opportunity for clinicians to develop, but can nonetheless be tough and demanding. As a foundation trainee, I spent 8 months working in the emergency department after the suspension of foundation training rotations due to COVID-19. Despite the challenges, I thoroughly enjoyed my time and feel that the things I learnt will make me both a better doctor and colleague in my future clinical practice. With this in mind, here are ten tips I would have loved to know before starting emergency medicine to maximise the opportunities, stay safe and avoid burnout.

\section{Escalate}

If you have any concerns about a patient, always escalate to a senior colleague.

\section{Don't be afraid of resuscitation areas}

It can be daunting, but try to be actively involved; there are always senior colleagues for support.

\section{Be annual leave savvy}

Book annual leave early to maximise your chance of getting the time off when you want (and need) it.

\section{Get enough sleep}

Switching between day and night shifts can be exhausting. Try to find a routine that suits you and stick to it.

\section{Don't dodge patients}

Don't skip patients presenting with a symptom you are underconfident with (temptation will be rife). It is an opportunity to learn and expand your skillset.


foundation trainee, St Bartholomew's Hospital, London, UK

\section{Seek out the guidelines}

They exist for just about everything - use them, they are your friend.

\section{Remember to eat and drink}

Make sure you eat and stay hydrated. Take a full bottle of water and sip regularly throughout the day.

\section{Ask, ask, ask}

When discussing patients with senior colleagues, don't be afraid to ask why they want to know things you hadn't thought of. It will help you to learn a little from every patient.

\section{Expand your practical skillset}

Use the time to practise skills and acquire new ones - there will be numerous opportunities.

\section{Tailor the opportunity to you}

If you already have a career path in mind, you can tailor your experience towards this using your ePortfolio, undertaking relevant quality improvement projects and finding interesting case reports.

Address for correspondence: Dr Lianne Fakes, Intensive Care Unit, St Bartholomew's Hospital, West Smithfield, London EC1A 7BE, UK.

Email: lianne.fakes@nhs.net 